\title{
TEN-YEAR EXPERIENCE WITH SURGICAL TREATMENT OF PARTIAL ATRIOVENTRICULAR SEPTAL DEFECT: RISK FACTORS IN THE EARLY POSTOPERATIVE PERIOD
}

Christophe Baufreton, MD

Didier Journois, $\mathrm{MD}^{\mathrm{b}}$

Francine Leca, MD ${ }^{\mathrm{a}}$

Wassim Khoury, MD ${ }^{\text {a }}$

Daniel Tamisier, $\mathrm{MD}^{\mathrm{a}}$

Pascal Vouhé, $\mathrm{MD}^{\mathrm{a}}$
Partial atrioventricular septal defects are electively repaired with good results. However, recent reports suggest that such repair is potentially a high-risk surgical procedure. Our aim was to determine the risk factors of adverse outcome early after surgical treatment of atrioventricular septal defects in our hospital. A retrospective study was done in 100 consecutive patients from 2 months to $\mathbf{5 0 . 6}$ years old (median 3.6 years) who underwent surgical correction between January 1984 and December 1993. An intermediate form of the lesion was noted in $31 \%$ of cases. Congestive heart failure occurred in $\mathbf{5 0 \%}$ of cases. Preoperative left atrioventricular valve incompetence (moderate to severe) was present in $63 \%$ of patients. Severe abnormalities of left subvalvular apparatus were noted in $28 \%$ of patients. The cleft of the left atrioventricular valve was closed in $76 \%$ of cases. The study was done to determine risk factors associated with hospital mortality $(13 \%)$, postoperative residual left atrioventricular valve incompetence $(23 \%)$, and early reoperation $(14 \%)$ within the first 30 postoperative days. Univariate analysis showed that age at the date of operation and cleft closure were not related to an early adverse outcome. A stepwise logistic regression with variables selected by univariate analysis identified infections and severe abnormalities of left subvalvular apparatus as predictive factors of early death (odds ratios, 28.07 and 6.18, respectively), preoperative left atrioventricular valve regurgitation as a predictive factor of residual postoperative left atrioventricular valve regurgitation (odds ratio, 5.34), and severe abnormalities of left subvalvular apparatus as a predictive factor of early reoperation (odds ratio, 5.27). These results emphasize the importance of the severity of the morphologic features of the left subvalvular apparatus, the occurrence of early postoperative infections, and the presence of residual left atrioventricular valve regurgitation as risk factors in the early period after surgical correction of partial atrioventricular septal defects. (J Thorac Cardiovasc Surg 1996;112:14-20)
A trioventricular septal defects (AVSDs), which consist of abnormalities of both the cardiac septum and the atrioventricular (AV) valves, have been surgically repaired for the past three decades. AVSDs can be classified into complete or partial

From the Departments of Cardiovascular Surgery ${ }^{\mathrm{a}}$ and Anesthesiology, ${ }^{\mathrm{b}}$ Hôpital Laennec, Paris, France.

Received for publication July 5, 1995; revisions requested August 17, 1995; revisions received Oct. 28, 1995; accepted for publication Nov. 10, 1995.

Address for reprints: Francine Leca, MD, Department of Cardiovascular Surgery, Hôpital Laennec, 42 rue de Sèvres, 75007 Paris, France.

Copyright (C) 1996 by Mosby-Year Book, Inc.

$0022-5223 / 96 \$ 5.00+0 \quad \mathbf{1 2 / 1 / 7 0 6 0 2}$ forms depending on the presence of one or two valve outlets. In addition, the presence of a cleft in the anterior leaflet of the left AV valve is common to both forms. Numerous studies have demonstrated the importance of left $\mathrm{AV}$ valve regurgitation on clinical outcome. ${ }^{1-5}$ However, despite different surgical approaches to repair of the left AV valve, these do not appear to decrease left AV valve regurgitation, because the pathophysiologic features of this disorder are still not totally understood. ${ }^{2}$ Even for partial AVSD, the early outcome of surgical correction for these defects has raised some concern. The aim of this study was therefore to determine the risk factors involved in adverse early outcome for surgical repair of partial AVSD. 


\section{Patients and methods}

Between January 1984 and December 1993, 100 consecutive patients were operated on because of partial (69\%) or intermediate (31\%) AVSD at Laennec Hospital (Paris, France). Patients with the partial form of AVSD were those who had two valve orifices associated with a cleft of the left $A V$ valve. Patients with intermediate forms of AVSD were those with a small ventricular septal defect associated with two valve orifices and with a cleft of the left AV valve leading to use of a surgical approach similar to that used for patients with partial forms. Patients with complete forms of AVSD (and thus a single valve outlet) were excluded from the study, as were those with an associated complex congenital lesion. The ages of patients ranged from 2 months to 50.6 years (median 3.6 years; 25 th and 75 th percentiles, 1.06 and 1.08 years, respectively). Down syndrome was present in nine cases ( 5 intermediate and 4 partial AVSD). At the time of operation, $50 \%$ of patients had already had one or several episodes of congestive heart failure (CHF).

Catheterization data, echocardiograms, and operative and hospital records were reviewed for all patients. Data on the occurrence and severity of preoperative $A V$ valve regurgitation were available in all patients for the left $\mathrm{AV}$ valve lesions and in $80 \%$ of patients for the right $A V$ valve lesions. In accordance with previous reports in the literature, assessment of left AV valve regurgitation was based on a subjective scale (grade 0 to 4 ). ${ }^{2}$ The regurgitation was considered significant in cases assigned grades from 2 to 4 (moderate to severe). Preoperative left AV valve regurgitation was noted in $63 \%$ of cases (25 grade 2, 16 grade 3 , and 22 grade 4 ). Pulmonary artery hypertension (PAH), defined as a systolic pulmonary artery pressure greater than $30 \mathrm{~mm} \mathrm{Hg}$, was present in $48(51.6 \%)$ of 93 patients and reached $50 \mathrm{~mm} \mathrm{Hg}$ or more in $13(14 \%)$ cases before the intervention.

The morphology of the left subvalvular apparatus was classified with data obtained from operative records. Abnormal morphologic features of the subvalvular apparatus have been previously described in patients with partial AVSD, ${ }^{6-8}$ and thus only severe abnormalities were retained for study as follows. Rudimentary or absent chordal apparatuses were defined as malformed. Those directly inserted into the undersurface of the leaflet instead of the margin were considered as chordal malpositions. Malformations and malpositions of the chordal apparatuses were grouped together. Malformations of papillary muscles included abnormally thick muscles and multiple thin muscles with abnormal insertions into the ventricular wall. Only extreme malpositions of the papillary muscles, such as extreme lateralization or single papillary muscle, were retained. Left AV valves with potentially parachute structure were also separately noted. These severe abnormalities of the left subvalvular apparatus are shown in Table $I$ and were present in several patients. The left AV valve morphologic features were also noted from operative records and were in agreement with the description of Becker and Anderson. ${ }^{8}$ Basically, the "ostium primum" was associated with a cleft of the left AV valve, separated from the right AV valve by a connecting tongue of the bridging leaflets. Other abnor-
Table I. Morphologic abnormalities associated with partial AVSD

\begin{tabular}{lc}
\multicolumn{1}{c}{ Associated cardiac abnomalities } & $\begin{array}{c}\text { No. of } \\
\text { cases }\end{array}$ \\
\hline Left subvalvular apparatus & 28 \\
Malformations or malposition of chordae & 20 \\
Malformations of papillary muscles & 17 \\
Malpositions of papillary muscles or single & 6 \\
papillary muscle & \\
Potentially parachute left AV valve & 5 \\
Left AV valve & 13 \\
Small inferior bridging leaflet & 7 \\
Double orifice & 5 \\
Accessory cleft of left AV valve & 1 \\
Other & \\
Left superior vena cava & 8 \\
Pulmonary valve stenosis & 5 \\
Anomalous systemic or pulmonary venous return & 6 \\
Coarctation of the aorta & 1 \\
Dilated cardiomyopathy & 1 \\
Single atrium & 3 \\
\hline
\end{tabular}

malities of the left AV valve or of the heart are also shown in Table I.

Surgical repair was done with the aid of cardiopulmonary bypass with transatrial bicaval cannulation and moderate hypothermia. Until 1989, myocardial protection was achieved with the aid of multidose cold crystalloid cardioplegic solution $\left(4^{\circ} \mathrm{C}\right)$ administered in the anterograde manner. Since then, this has been replaced by the use of cold blood cardioplegic solution followed by warm modified blood reperfusion. Since 1990, ultrafiltration has been done regularly during rewarming. The cleft of the left AV valve was repaired in $76 \%$ of cases. However, this was not complete in $12 \%$ to avoid any stenosis of the left $\mathrm{AV}$ valve orifice. A valve repair or a commissuroplasty, or both, was done in 16 patients. Two patients required left AV valve replacement with a mechanical prosthesis (St. Jude Medical [St. Jude Medical, Inc., St. Paul, Minn.] size 33 and CarboMedics [CarboMedics, Inc., Austin, Tex.] size 16). Sixteen patients with a small ventricular septal defect in the intermediate group ( $n=31$ ) required surgical closure because the defect did not close spontaneously. Left AV valve competence was tested by injecting cold saline solution into the left ventricle. The atrial septal defect was repaired with use of a heterologous pericardial patch. So that injury to the AV node could be avoided, the atrial septum was repaired in such a way as to direct the coronary sinus into the left atrium in $42 \%$ of cases. Three patients required a De Vega annuloplasty. None of the patients received treatment with nitric oxide inhalation during the stay in the intensive care unit. Postoperative conduction disturbances occurred in five patients, with three having complete heart block.

Perioperative death was defined as death that occurred within the first 30 postoperative days. Early reoperations were defined as those that occurred within 30 days. Perioperative infections were included if they were thought to affect prognosis (septicemia, septic shock, endocarditis, mediastinitis, focal infection with sepsis). 
Table II. Causes of perioperative death

\begin{tabular}{|c|c|c|c|c|}
\hline Patient & Causes & Days postop. & $S V A$ & $I N F$ \\
\hline 1 & Cardiac failure & 1 & Yes & No \\
\hline 2 & Cardiac failure & 1 & No & No \\
\hline 3 & Cardiac failure & 1 & Yes & No \\
\hline 4 & Low cardiac output after CPB for reoperation & 12 & Yes & No \\
\hline 5 & Septic shock during circulatory support & 3 & No & Yes \\
\hline 6 & Cardiogenic + septic shock & 13 & Yes & Yes \\
\hline 7 & Cardiogenic + septic shock + decerebration & 14 & Yes & Yes \\
\hline 8 & Septic shock + hyperfibrinolysis & 2 & Yes & Yes \\
\hline 9 & Pulmonary infection + cardiac arrest & 22 & No & Yes \\
\hline 10 & Pulmonary edema + acidosis & 9 & Yes & No \\
\hline 11 & Pulmonary hypertensive crises (left $\mathrm{AV}$ valve regurgitation) & 2 & Yes & No \\
\hline 12 & Tamponade after left atrial catheter removal & 11 & Yes & No \\
\hline 13 & Bleeding + tamponade & 0.4 & No & No \\
\hline
\end{tabular}

$S V A$, Severe abnormalities of the left subvalvular apparatus; $I N F$, severe postoperative infection; $C P B$, cardiopulmonary bypass.

Table III. Variables associated with perioperative death by univariate analysis

\begin{tabular}{|c|c|c|}
\hline Variable & $\begin{array}{l}\text { Prevalence } \\
\quad(\%)\end{array}$ & $\begin{array}{c}p \\
\text { Value }\end{array}$ \\
\hline \multicolumn{3}{|l|}{ Infection } \\
\hline Yes & 71 & 0.0003 \\
\hline No & 9 & \\
\hline \multicolumn{3}{|c|}{ Severe abnormalities of left SVA } \\
\hline Yes & 32 & 0.0009 \\
\hline No & 6 & \\
\hline \multicolumn{3}{|l|}{ Early reoperation } \\
\hline Yes & 43 & 0.002 \\
\hline No & 8 & \\
\hline \multicolumn{3}{|c|}{$\begin{array}{l}\text { Severe preoperative left } A V \text { valve } \\
\text { regurgitation }\end{array}$} \\
\hline Yes & 32 & 0.006 \\
\hline No & 8 & \\
\hline \multicolumn{3}{|c|}{$\begin{array}{l}\text { Moderate or severe preoperative right } \mathrm{AV} \\
\text { valve regurgitation }\end{array}$} \\
\hline Yes & 36 & 0.01 \\
\hline No & 6 & \\
\hline \multicolumn{3}{|l|}{ Preoperative PAH } \\
\hline Yes & 19 & 0.027 \\
\hline No & 4 & \\
\hline \multicolumn{3}{|c|}{ Postoperative left AV valve regurgitation } \\
\hline Yes & 26 & 0.03 \\
\hline No & 9 & \\
\hline
\end{tabular}

Percentages indicate prevalence of perioperative death when studied variable was present (yes) or not present (no).

$S V A$, Subvalvular apparatus. Values determined by $\chi^{2}$ or Fisher's exact test.

Data were analyzed with the SPSS software package (SPSS, Inc., Chicago, Ill.). ${ }^{9}$ Univariate analysis of preoperative, procedure-related, and postoperative variables (see appendix) was done to investigate associations with early outcome, including perioperative death, left $\mathrm{AV}$ valve residual regurgitation, and reoperation. Qualitative variables were analyzed with $\chi^{2}$ or Fisher's exact test and quantitative variables with Mann-Whitney or Wilcoxon tests when appropriate. Identification of trends over time was done by Mantel-Haenszel $\chi^{2}$ analysis. A $p<0.05$ level was considered statistically significant. The selected variables were included in a stepwise logistic regression model to determine the predictive factors of perioperative death, residual left $\mathrm{AV}$ valve regurgitation, and early reoperation. When specific solutions to the model equations were found, the odds ratios were calculated by raising $\mathrm{e}^{\beta}$, where $\beta$ represents the parameter estimate for the risk factor.

\section{Results}

Perioperative mortality. There were 13 early postoperative deaths (13\%) (Table II). Although tendencies were observed, no statistical significance was observed between perioperative mortality and age $(p=0.06)$, previous episodes of $\mathrm{CHF}(20 \%$ versus $6 \%$ when CHF did not occur; $p=0.07$ ), intermediate forms of AVSD (22\% versus 9\% with partial forms; $p=0.06$ ), and other left AV valve lesions associated with the cleft $(23 \%$ versus $12 \%$ when not present; $p=0.16$ ). Closure of the cleft of the left AV valve was not associated with a significant variation in perioperative mortality $(15 \%$ versus $8 \%$ if not closed; $p=0.22$ ). There was no relationship between perioperative mortality and time in the study period $(p=0.34)$.

Seven variables were retained by univariate analysis as determinants of perioperative mortality (Table III). After multivariate analysis, only severe postoperative infection and severe abnormalities of the left subvalvular apparatus were retained by the model as predictive risk factors for perioperative death (Table IV).

Seven severe infections occurred during the postoperative period. In five cases, these contributed to the death of the patient. They were as follows: four cases of septic shock (1 patient survived), 1 case of mediastinitis (survived), 1 case of endocarditis asso- 
Table IV. Early postoperative outcome by multivariate logistic regression analysis

\begin{tabular}{|c|c|c|c|c|}
\hline Outcome & Risk factors & Parameter estimate & $p$ Value & Odds ratio \\
\hline \multirow[t]{2}{*}{ Perioperative death } & Severe infection & $3.33 \pm 1.19$ & 0.0054 & 28.07 \\
\hline & Left SVA abnormalities & $1.82 \pm 0.58$ & 0.0019 & 6.18 \\
\hline $\begin{array}{c}\text { Postoperative left } \mathrm{AV} \\
\text { valve regurgitation }\end{array}$ & $\begin{array}{l}\text { Preoperative left } \mathrm{AV} \\
\text { valve regurgitation }\end{array}$ & $1.67 \pm 0.61$ & 0.0064 & 5.34 \\
\hline Early reoperation & Left SVA abnormalities & $1.66 \pm 0.62$ & 0.0077 & 5.27 \\
\hline
\end{tabular}

$S V A$, Subvalvular apparatus. Parameter $x$ estimation must be raised to $e^{x}$ to determine odds ratio.

ciated with septicemia, and one case of pulmonary infection with impaired respiratory function. Preoperative PAH had been noticed in each case $(p=$ 0.012 ) and an intermediate form of AVSD in six cases $(p=0.003)$. No statistical association was found between the age of the patients and the prevalence of infections $(p=0.47)$.

Left AV valve regurgitation. Residual left $\mathrm{AV}$ valve regurgitation remained moderate to severe in 23 patients $(23 \%)$. Univariate analysis showed five variables associated with such an outcome (Table V). There was no relationship between left AV valve regurgitation and time in the study period. There was no significant relationship between postoperative left AV valve regurgitation and type of AVSD (26\% versus $22 \%$ for intermediate and partial forms, respectively; $p=0.84$ ) or the closure of the left AV valve (24\% versus 21\% when not closed; $p=$ 0.99). On the other hand, if the closure of the cleft of the left $\mathrm{AV}$ valve to avoid valve stenosis was not thought to be complete by the surgeon, the left AV valve was more often incompetent after the operation (Table V).

Logistic regression showed that preoperative left $A V$ valve regurgitation was the only predictive risk factor of residual postoperative left $\mathrm{AV}$ valve regurgitation (Table IV).

Statistical analysis of preoperative left AV valve regurgitation showed significant associations with severe left subvalvular apparatus abnormalities (82\% when present versus $56 \%$ if not; $p=0.013$ ) and preoperative PAH (63\% versus $32 \%$ if no PAH; $p=0.005$ ) but not with any other abnormalities of the left $\mathrm{AV}$ valve $(77 \%$ versus $61 \%$ when noticed; $p=0.36$ ) or type of AVSD (62\% for partial forms versus $65 \%$ for intermediate forms; $p=0.83$ ).

Early reoperation. Early reoperation was done in 14 patients (14\% for the following reasons: persistence of severe left AV valve regurgitation $(n=7)$, need for circulatory support $(n=2)$, interatrial residual shunt $(n=2)$, and excessive bleeding ( $n=$
Table V. Variables associated with postoperative left $A V$ valve regurgitation by univariate analysis

\begin{tabular}{lcc}
\hline \multicolumn{1}{c}{ Variable } & $\begin{array}{c}\text { Prevalence } \\
(\%)\end{array}$ & $\begin{array}{c}p \\
\text { Value }\end{array}$ \\
\hline $\begin{array}{l}\text { Preoperative left AV valve regurgitation } \\
\quad \text { Yes }\end{array}$ & 35 & 0.001 \\
$\quad$ No & 3 & \\
Severe abnormalities of left SVA & 46 & 0.001 \\
$\quad$ Yes & 14 & \\
No & & \\
Left AV valve repair, commissuroplasty, & & \\
or both & 50 & 0.007 \\
Yes & 18 & \\
No & & \\
Associated abnormalities of left AV & & \\
$\quad$ valve & 54 & 0.008 \\
Yes & 18 & \\
No & & \\
Incomplete closure of cleft of left AV & & \\
$\quad$ valve & 50 & 0.024 \\
Yes & 19 & \\
No &
\end{tabular}

Percentages indicate prevalence of postoperative left AV valve regurgitation when studied variable was present (yes) or not present (no). SVA, Subvalvular apparatus. Values determined by $\chi^{2}$ or Fisher's exact test.

3). Two of these patients required left AV valve replacement with a mechanical prosthesis. In total, four patients needed prosthetic valve replacement, and all of these had had severe abnormalities of the left subvalvular apparatus at presentation $(p=$ $0.005)$. By univariate analysis, four variables were associated with the need for early reoperation (Table VI). Nonclosure of the cleft of the left AV valve was not significantly associated with this outcome ( $21 \%$ versus $12 \%$ when closed; $p=0.31$ ). Conversely, as pointed out for postoperative left $\mathrm{AV}$ regurgitation, when the closure had not been completely accomplished, although the intention to treat the cleft was clear, the need for reoperation was more frequent.

The logistic regression model retained severe abnormalities of the left subvalvular apparatus as 
Table VI. Variables associated with early reoperation by univariate analysis

\begin{tabular}{lrc} 
Variable & $\begin{array}{c}\text { Prevalence } \\
(\%)\end{array}$ & $\begin{array}{c}p \\
\text { Value }\end{array}$ \\
\hline Postoperative left AV valve regurgitation & & \\
Yes & 39 & 0.0003 \\
$\quad$ No & 7 & \\
Associated abnormalities of left AV & & \\
$\quad$ valve & 39 & 0.01 \\
Yes & 10 & \\
No & & \\
Severe abnormalities of left SVA & 29 & 0.01 \\
Yes & 8 & \\
No & & \\
Incomplete closure of cleft of left AV & & \\
valve & 33 & 0.024 \\
Yes & 9 & \\
No &
\end{tabular}

Percentages indicate prevalence of early reoperation when studied variable was present (yes) or not present (no). $S V A$, Subvalvular apparatus. Values determined by $\chi^{2}$ or Fisher's exact test.

the only predictive risk factor of early reoperation (Table IV).

\section{Discussion}

The occurrence of severe abnormalities of the left subvalvular apparatus contributes to understanding of the pathophysiologic factors leading to perioperative death and early reoperation. In addition, such abnormalities are associated with preoperative left AV valve regurgitation, which has a well-known association with residual left AV valve regurgitation. Therefore, as a main risk factor demonstrated by our study, left subvalvular apparatus abnormalities represent the anatomicopathologic substratum that determines the early outcome of surgical treatment for partial AVSD.

Several retrospective studies have pointed out risk factors of partial AVSD. ${ }^{1,3,4,10-12}$ The severity of $\mathrm{CHF},{ }^{1,4}$ levels of pulmonary artery pressures and pulmonary resistances, ${ }^{10-12}$ degree of left $\mathrm{AV}$ valve regurgitation, ${ }^{1,4,12}$ age, 1, 4, 11 date of operation,, 11 and low body surface area ${ }^{12}$ have been previously reported to be clinical risk factors for perioperative mortality. However, morphologic lesions have been less frequently identified as predictive risk factors. Studer and associates ${ }^{1}$ showed that patients with ventricular septal defects or double-orifice left AV valve are at high risk for the surgical procedure. More recently, Manning and colleagues ${ }^{13}$ identified a subset of patients with primum atrial septal defect characterized by occurrence of CHF in the first year of life. This group of patients had a higher preva- lence of left-sided obstructive lesions, followed by higher rates of operative mortality (36\%) and need for reoperation $(63 \%)$, whereas other patients were electively operated on with good results. Basically, in partial AVSD, the left chordae are often short, and leaflet motion is thus restricted. The papillary muscles are also displaced within the left ventricle. ${ }^{6-8}$ Therefore abnormalities of the left subvalvular apparatus are frequent and difficult to classify. For this reason, only the most severe abnormalities of the left subvalvular apparatus were taken into consideration in our study, as recommended by Abbruzzese and colleagues. ${ }^{3}$ Such abnormalities seems to be prevalent in our group of patients. However, they are known to be more frequent in partial forms than in complete forms of AVSD. Penkoske and associates ${ }^{14}$ reported up to $20 \%$ of abnormalities of the left subvalvular apparatus in partial forms of AVSD and only 3.1\% in complete forms. Moreover, patients with Down syndrome are usually considered to be relatively protected from left-sided intraventricular lesions. In our series, the low incidence of Down syndrome could partly explain the prevalence of left-sided lesions and is indeed in agreement with results reported by Manning and colleagues. ${ }^{13}$ Some authors consider that these critical lesions of the left subvalvular apparatus cannot be readily controlled by common surgical techniques. ${ }^{6,15,16}$ and recommend proceeding to prosthetic valve replacement. ${ }^{5}$ However, left AV valve replacement in children, and particularly in infants, is associated with a high mortality rate, the need for anticoagulation, and a high rate of reoperation for prosthetic valve replacement related to growth. ${ }^{17-20}$ It is also associated with the theoretic risk of increasing left ventricular outflow tract obstruction. ${ }^{21}$ Our surgical approach was conservative with regard to preservation of the native left AV valve. This attitude could explain the higher prevalence of perioperative death and reoperation as compared with that of other groups that perform prosthetic valve replacement more frequently (from $5.5 \%$ to $12 \%)$. $3,5,10$

The importance of the left subvalvular apparatus in postoperative outcome is further emphasized by the fact that our results were not affected by the surgical approach used on the left AV valve (closure or nonclosure of the cleft of the left AV valve).

The relatively high prevalence of sepsis in our series has been an important cause of early postoperative death. PAH was significantly associated with postoperative infections. This is due to the increased 
duration of mechanical ventilation and intensive care unit stay associated with pulmonary hypertension. $^{22}$ Systemic sepsis was more frequent than locoregional infection (e.g., mediastinitis). However, the prevalence of infection seems to be more a result of the preoperative status of the patient than of a center effect. Indeed, during the study period when sepsis was most prevalent in patients with AVSD, sepsis in patients operated on because of transposition of the great arteries was only $2.3 \% .^{23}$ In this latter condition, most of the patients were neonates, which suggests that the risk of a postoperative infection developing could be related to the duration of exposure to a congenital heart defect. However, in our study, the results could not identify a close relationship between age and infection. This phenomenon might be masked by the conventional grouping of intermediate forms with partial forms of AVSD in opposition to complete forms of AVSD. ${ }^{21}$ Therefore the systemic effect of infection might be worse in patients with PAH than it is when examined according to the age of the patient. However, the infection rate was relatively higher than that reported by others. ${ }^{1}$ This could be explained by the higher prevalence of chronic infections often observed in Down syndrome. ${ }^{24}$ It may also be due to the poor nutritional status of children often referred to our institution from countries with poor economic conditions.

In contrast to results in other reports (which have been optimized by changes in surgical practice during the past 20 -year period), $1,2,5,11$ our results have not changed with time. Our study was limited to the past 10 years and the surgical and postoperative management procedures remained standardized.

In conclusion, clinical features of partial AVSD are markedly variable. Some lesions are relatively well tolerated until an advanced adult age and others have a bad prognosis whatever the surgical treatment. This study emphasized the importance of the left subvalvular apparatus with regard to the perioperative outcome of partial AVSD. The presence of these lesions mandates particular attention to the surgical procedure used in each individual case. Indeed, severe abnormalities of the left subvalvular apparatus might only be handled by left $\mathrm{AV}$ valve replacement rather than reconstructive techniques with the left AV valve. Particular attention has to be directed against surgical infection inasmuch as infection results in a poor outcome in this group of patients.
We thank Walid C. Dihmis, MD, for his help in reviewing the manuscript.

\section{REFERENCES}

1. Studer M, Blackstone HE, Kirklin JW, et al. Determinants of early and late results of repair of atrioventricular septal (canal) defects. J Thorac Cardiovasc Surg 1982;84:523-42.

2. Hanley FL, Fenton KN, Jonas RA, et al. Surgical repair of complete atrioventricular canal defects in infancy: twentyyear trends. J Thorac Cardiovasc Surg 1993;106:387-97.

3. Abbruzzese PA, Napoleone A, Bini RM, Annecchino FP, Merlo M, Parenzan L. Late left atrioventricular valve insufficiency after repair of partial atrioventricular septal defects: anatomical and surgical determinants. Ann Thorac Surg 1990;49:111-4.

4. King RM, Francisco JP, Danielson GK, Schaff HV, Julsrud PR, Feldt RH. Prognostic factors and surgical treatment of partial atrioventricular canal. Circulation 1986;74(Suppl): I42-6.

5. Lozano C, Rovirosa M, Reig J, Salva JA. Surgery of atrioventricular septal defects: review of the first 100 cases. Eur J Cardiothorac Surg 1990;4:359-64.

6. Carpentier A. Surgical anatomy and management of the mitral component of atrioventricular canal defects. In: Anderson RH, Shinboune EA, eds. Pediatric cardiology. London: Churchill Livingstone, 1978:477-90.

7. Silverman NH, Zuberbuhler JR, Anderson RH. Atrioventricular septal defects: cross-sectional echocardiographic and morphologic comparisons. Int J Cardiol 1986;13:30931.

8. Becker AE, Anderson RH. Atrioventricular septal defects: what's in a name? J Thorac Cardiovasc Surg 1982;83:461-9.

9. Norusis MJ. Advanced statistics student guide: SPSS statistical data analysis. Chicago: SPSS, Inc., 1990:119-46.

10. Losay J, Rosenthal A, Castañeda AR, Bernhard WH, Nadas AS. Repair of atrial septal defect primum: results, course, and prognosis. J Thorac Cardiovasc Surg 1978;75: 248-54.

11. McGrath LB, Gonzalez-Lavin L. Actuarial survival, freedom from reoperation, and other events after repair of atrioventricular septal defects. J Thorac Cardiovasc Surg 1987;94:58290.

12. Rizzoli G, Mazzuco A, Brumana T, et al. Operative risk of correction of atrioventricular septal defects. Br Heart $\mathrm{J}$ 1984;52:258-65.

13. Manning PB, Mayer JE, Sanders SP, et al. Unique features and prognosis of primum ASD presenting in the first year of life. Circulation 1994;90(Suppl)II30-5.

14. Penkoske PA, Neches WH, Anderson RH, Zuberbuhler JR. Further observations on the morphology of atrioventricular septal defects. J Thorac Cardiovasc Surg 1985;90: 611-22.

15. David I, Castañeda AR, Van Praagh R. Potentially parachute mitral valve in common atrioventricular canal. J Thorac Cardiovasc Surg 1982;84:178-86.

16. Tandon R, Moller JH, Edwards JE. Single papillary muscle of the left ventricle associated with persistent common atrioventricular canal: variant of parachute mitral valve. Pediatr Cardiol 1986;7:111-4.

17. Kadoba K, Jonas RA, Mayer JE, Castañeda AR. Mitral valve replacement in the first year of life. J Thorac Cardiovasc Surg $1990 ; 100: 762-8$. 
18. Schachner H, Salomon J, Levinsky L. Prosthetic valve replacement in infants and children. Thorac Cardiovasc Surg 1984;25:537-44.

19. Bradley LM, Midgley FM, Watson DC, Getson PR, Scott LP. Anticoagulation therapy in children with mechanical prosthetic cardiac valves. Am J Cardiol 1985;56:533-5.

20. Caillat M, Leca F, Thibert M, Tamisier D, Meguid A, Vouhé $P$, et al. Remplacement valvulaire mitral dans le canal atrio-ventriculaire. Arch Mal Coeur 1990;83:711-5.

21. Kirklin JW, Barratt-Boyes BG. Atrioventricular canal defect. In: Kirklin JW, Barratt Boyes BG, eds. Cardiac surgery. 2nd ed. New York: Churchill Livingstone, 1993:693-747.

22. Hopkins RA, Bull C, Haworth S, De Leval MR, Stark J. Pulmonary hypertensive crises following surgery for congenital heart defects in young children. Eur J Cardiothorac Surg 1991;5:628-34.

23. Vouhé PR, Haydar A, Ouaknine R, Albanese SB, Mauriat $\mathrm{Ph}$, Pouard Ph, et al. Arterial switch operation: a new technique of coronary transfer. Eur J Cardiothorac Surg 1994;8:74-8.

24. Oster J, Mikkelsen M, Nielsen A. Mortality and life-table in Down's syndrome. Acta Paediatr Scand 1975;64:322-6.

\section{Appendix}

Variables examined by univariate analysis were as follows:

Age at time of operation

One or more episodes of preoperative CHF

Down syndrome

Cardiothoracic ratio $>0.55$

Atrial fibrillation

Intermediate form of AVSD

Preoperative left AV valve regurgitation

Severe abnormalities of left subvalvular apparatus

Other abnormalities of left $\mathrm{AV}$ valve

Preoperative right AV valve regurgitation

Preoperative PAH

Left superior vena cava

Incomplete cleft of left $\mathrm{AV}$ valve

Nonclosure of cleft of left AV valve

Incomplete closure of cleft of left $A V$ valve

Ventricular septal defect closure

Left AV valve repair or commissuroplasty, or both

Postoperative left AV valve regurgitation

Early reoperation

Severe postoperative infection 